\title{
DIREITO AUTORAL E ECAD: ANÁLISE JURISPRUDENCIAL DO PAPEL DO ESCRITÓRIO CENTRAL DE ARRECADAÇÃO E DISTRIBUIÇÃO NA COBRANÇA JUDICIAL PELA EXECUÇÃO PÚBLICA DE OBRAS MUSICAIS E CONGÊNERES
}

\author{
Caio Valério Gondim Reginaldo Falcão \\ Especialista em Direito Empresarial (PUC/SP) e em Direito Autoral \\ (Universidade de Warwick - Reino Unido). Advogado. \\ Sidney Soares Filho \\ Mestre em Direito Constitucional (Unifor). Professor da graduação \\ e pós-graduação da Unifor. \\ Sumário: Introdução. 1. A Proteção Constitucional e Legal do Direito \\ Autoral. 2. O Escritório Central de Arrecadação e Distribuição. \\ 3. Análise Jurisprudencial da Cobrança do Direito Autoral. Conclusão. \\ Bibliografia. Referências.
}

Resumo: O Poder Constituinte Originário elevou a nível constitucional, sendo, inclusive, direito fundamental, a proteção do direito artístico no que concerne a utilização, publicação e reprodução de suas obras. Dessa forma, a atual Lei dos Direitos Autorais, Lei Federal nº 9.610/98, cuidou em dar especial proteção aos direitos dos criadores de obras artísticas, garantindo, inclusive, a contraprestação financeira ao autor pelo uso de sua obra. Assim, o Escritório Central de Arrecadação e Distribuição (ECAD) foi mantido por esta lei, no sentido de garantir o recebimento, por parte do autor, o que lhe for de direito pela utilização de sua obra. O presente trabalho, portanto, através de pesquisas bibliográficas, legais e jurisprudenciais, se propõe a analisar a atuação do ECAD na cobrança pela utilização de obras musicais, dando enfoque, principalmente, no que diz respeito ao posicionamento dos Superior Tribunal de Justiça e de Tribunais de $2^{\text {a }}$ (segunda) instância sobre essa cobrança.

Palavras-chave: Direito autoral. Autor. ECAD. Cobrança judicial.

\section{INTRODUÇÃo}

A Constituição Federal de 05 de outubro de 1988 confere exclusividade ao autor sobre suas obras, no art. $5^{\circ}$, inciso XXVII, inserido dentro Dos Direitos e Deveres Individuais e Coletivos, assegurando ao criador o direito exclusivo de utilização, publicação ou reprodução de suas obras, transmissível aos herdeiros pelo tempo que a lei fixar. 
Foi nessa tônica que a Lei n. 9.610/98, seguindo a orientação já existente na Lei no 5.988, conferiu exclusividade ao autor da criação intelectual para decidir sobre sua exploração econômica, condicionando a utilização por terceiros à prévia e necessária autorização do criador.

Dessa forma, o autor da obre artística tem direito a receber contraprestação pecuniária pela utilização de sua obra por parte do usuário. Essa prerrogativa encontra guarida na Constituição Federal, a qual traçou as diretrizes básicas e indispensáveis à proteção de criações intelectuais garantindo, em seu artigo 5", incisos XXVII e XXVIII, letra "b", que, em regra, somente o criador pode fixar o preço pela utilização de sua obra.

Assim, para cuidar da Arrecadação dos Direitos Autorais, existe o ECAD (Escritório de Arrecadação e Distribuição), o qual é competente, de acordo com as disposições legais, para tomar providências no âmbito judicial e extrajudicial, no intuito de ver satisfeitos os direitos dos autores de músicas em relação à cobrança do direito autoral.

O órgão soberano dessa instituição é a Assembléia Geral do ECAD, composta pelas associações que representam os titulares de obras musicais, lítero-musicais e fonogramas, sendo ela quem faz valer o direito dos titulares, estabelecendo os critérios e fixando, na maioria das vezes, o preço pela utilização pública de obras musicais de seus filiados, valores esses que são exigidos pelo ECAD.

É importante mencionar, inclusive, que a Constituição Federal de 05 de outubro de 1988, em seu artigo $5^{\circ}$, inciso XVIII, com referência à situação jurídica das associações civis, disciplinou que a criação de associações e, na forma da lei, a de cooperativas independem de autorização, sendo vedada a interferência estatal em seu funcionamento. Desse modo, tem-se a legitimidade constitucional da existência do ECAD, instituição que tem atuado amplamente na defesa dos direitos autorais, em especial, no âmbito judicial.

Portanto, o presente artigo cuida em fazer uma análise jurisprudencial da atuação do ECAD na cobrança dos direitos autorais. Para tanto, foi desenvolvida pesquisa bibliográfica, sendo consultados livros e artigos científicos. E documental, tendo em vista a utilização de pesquisas online, com informações jurisprudenciais, dentre outros que tratam sobre o tema, sempre procurando fazer uso de material que ainda não sofreu tratamento analítico.

O trabalho está desenvolvido em três tópicos: o primeiro, aborda a proteção constitucional e legal do direito autoral; já o segundo, trata do Escritório Central de Arrecadação e Distribuição (ECAD); e, por último, o terceiro tem como foco a análise jurisprudencial da cobrança do direito autoral relacionado à música.

\section{A proteção constitucional e legal ao Direito Autoral}

A Constituição Federal de 1988 confere exclusividade ao autor sobre suas obras, estando tal proteção inserida no art. $5^{\circ}$, inciso XXVII, sob a rubrica Dos Direitos e Deveres Individuais e Coletivos, na seguinte forma: "Aos autores pertence o direito exclusivo de utilização, publicação ou reprodução de suas obras, transmissível aos herdeiros pelo tempo que a lei fixar"

Percebe-se a ampla proteção que o legislador constituinte deu aos direitos autorais, inserindo-os no rol de direitos e garantias fundamentais, de forma a assegurar aos criadores de músicas de demais artistas a remuneração pela utilização de sua obra. Aliás, sobre o tema, o próprio Supremo Tribunal Federal (STF) editou a Súmula $n^{\circ}$ 386, a qual preceitua da seguinte forma: "Pela execução de obra musical por artistas remunerados é devido direito autoral, não exigível quando a orquestra for de amadores." 
Ademais, na própria Constituição de 1988, é assegurado não só o direito autoral, em sentido estrito, conforme foi visto, mas também "o direito de fiscalização do aproveitamento econômico das obras que criarem ou de que participarem aos intérpretes e às representações sindicais e associativas", no mesmo Art. $5^{\circ}$, mas dessa vez no inciso XXVIII.

Demonstrando, então, a importância na proteção de obras intelectuais, o Constituinte Originário elevou a nível Constitucional a EXCLUSIVIDADE, em regra, do autor de obras intelectuais exercer seus direitos, o que significa ser ele, a única pessoa que pode exercer as prerrogativas advindas das obras protegidas.

É nesse sentido que, atualmente, há a Lei Federal nº. 9.610/98, denominada Lei de Proteção aos Direitos Autorais, a qual, em seu preâmbulo, preceitua da seguinte forma: "altera, atualiza e consolida a legislação sobre direitos autorais e dá outras providências."

Desse modo, tal legislação traz ampla proteção ao direito autoral, legitimando, inclusive, o ECAD (Escritório Central de Arrecadação e Distribuição), para a arrecadação de tais direitos e que será desenvolvido mais adiante.

A Lei $n^{\circ}$ 9.610/98 impõe, entre outros aspectos, a obrigação legal direcionada a todos as pessoas de não utilizarem as obras musicais em suas programações sem a devida autorização dos titulares de direitos autorais. Isso se dá pelo fato de ninguém poder ser obrigado a ceder ou liberar seus direitos, sendo a obra artística, mesmo a música. Esta, inclusive, é uma propriedade e compreendida como bem móvel, por ficção jurídica tanto da Lei de Direitos Autorais, como do Código Civil, nos seguintes termos

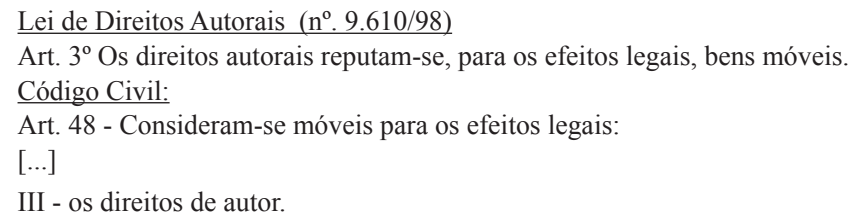

Portanto, os direitos autorais são considerados bens móveis, merecendo especial proteção do legislador. No que diz respeito à música, o art. $7^{\circ}$, da Lei de Proteção aos Direitos Autorais, é preceituado da seguinte forma:

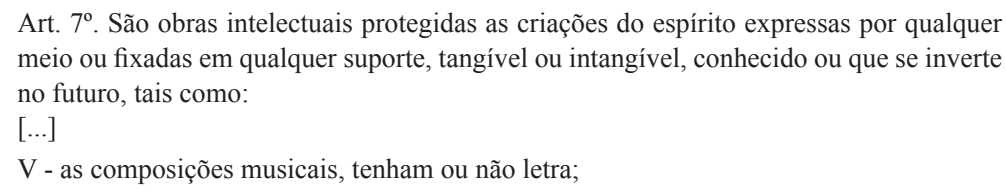
meio ou fixadas em qualquer suporte, tangível ou intangível, conhecido ou que se inverte no futuro, tais como:$$
[\cdots]
$$$$
\mathrm{V} \text { - as composições musicais, tenham ou não letra; }
$$

Vê-se, portanto, que a própria lei preserva os direitos inerentes à criação da música, dizendo, inclusive, que se trata de criações de espírito, verdadeira obra intelectual, tenha ou não letra.

É nesse sentido que os Arts. 28 e 29 do citado Diploma Legal, na mesma linha da sistemática anterior, qual seja as Leis n ${ }^{\circ}$ 5.998/73 e 4.944/66, ao tratar dos direitos patrimoniais dos autores de obras intelectuais, condiciona sua utilização à prévia e expressa autorização de seus autores e titulares. Isso porque somente a eles são deferidas todas as prerrogativas do domínio, podendo autorizar a utilização pública de suas criações mediante o recebimento de retribuição autoral. O Art. 28, dessa forma, preceitua "cabe ao autor direito exclusivo de utilizar, fruir e dispor da obra literária, artística ou científica”; já o Art. 29 dispõe da seguinte forma: "Depende de autorização prévia e expressa do autor a utilização da obra, por quaisquer modalidades, tais como: (...)". 
Vê-se, então, que a Lei de Proteção aos Direitos Autorais, em consonância com a ordem constitucional, protege a pessoa criadora da obra artística a utilização exclusiva de sua criação, podendo, inclusive, cobrar pelo uso por parte de terceiros.

Aliás, da mesma forma, o Art. 68 proíbe a utilização de composições musicais ou líteromusicais e fonogramas em representações, e execuções públicas sem a prévia e expressa autorização do autor ou titular dos direitos autorais. O dispositivo legal que está dentro do Capítulo, cujo título é "Da Comunicação ao Público" dispõe que sem a prévia e expressa autorização do autor ou titular, não poderão ser utilizadas obras teatrais, composições musicais ou lítero-musicais e fonogramas, em representações e execuções públicas, dispostivo este que será abordado mais adiante.

Os usuários de músicas, então, não podem promover a execução pública de obras musicais sem a autorização dos autores e demais, tendo OBRIGAÇÃO de apresentar antes de qualquer evento musical, a comprovação dos recolhimentos dos direitos autorais, conforme se infere da leitura do parágrafo $4^{\circ}$ do art. 68, o qual dispõe da seguinte forma: "Previamente à realização da execução pública, o empresário deverá apresentar ao escritório central, previsto no art. 99, a comprovação dos recolhimentos relativos aos direitos autorais."

Dessa forma, qualquer usuário de obras musicais, de acordo com a expressa vigência do art. 68, da Lei de Regência, está obrigado a exibir a necessária autorização prévia dos titulares, expedida pelo ECAD, para a utilização pública das composições alheias.

Assim, cabe aos titulares das obras musicais, através de sua Assembléia, composta das associações de titulares, o direito de fiscalização e aproveitamento econômico de suas obras e, sendo os direitos autorais violados, compete ao ECAD diligências no âmbito judicial e extrajudicial para ver sanada tal violação.

\section{O Escritório Central de Arrecadação e Distribuição (ECAD)}

A Constituição Federal de 05 de outubro de 1988, em seu artigo 5º inciso XVIII, com referência à situação jurídica das associações civis, disciplinou que a criação de associações e na forma da lei, a de cooperativas independem de autorização, sendo vedada a interferência estatal em seu funcionamento. Assim, com o objetivo de atuar na defesa dos direitos autorais, em especial, no âmbito judicial, foi instituído o Escritório Central de Arrecadação e Distribuição (ECAD), tema do presente tópico.

O ECAD é uma sociedade civil, pessoa jurídica de direito privado, portanto, instituída pela Lei Federal n ${ }^{\circ}$ 5.988/73 e mantida pela atual Lei de Direitos Autorais brasileira - 9.610/98. Foi criado, nos termos do Art. 99 deste preceito legal, "para a arrecadação e distribuição, em comum, dos direitos relativos à execução pública das obras musicais e lítero-musicais e de fonogramas, inclusive por meio da radiodifusão e transmissão por qualquer modalidade, e da exibição de obras audiovisuais."

Atualmente, o ECAD é administrado por dez associações de músicas, com sede na cidade do Rio de Janeiro, tendo 25 unidades arrecadadoras, 700 funcionários, 60 advogados prestadores de serviços e 131 agências autônomas instaladas em todos os Estados da Federação. De acordo com dados contidos em seu sítio eletrônico ${ }^{1}$, a instituição possui ampla cobertura em todo o Brasil.

Para realizar o controle de informações, o ECAD utiliza sistema de dados informatizado e centralizado, no qual há o cadastro de 245 mil titulares diferentes. Estão catalogadas, de acordo com sua página na internet, "1,75 milhão de obras, além de 760 mil fonogramas, que contabilizam todas as versões registradas de cada música"’2.

1 http://www.ecad.org.br/ViewController/publico/conteudo.aspx?codigo=16, acessado em 20 de novembro de 2010, às $15 \mathrm{~h}$

2 idem 
Essa numeração serve para que o ECAD, em sua competência legal, possa cobrar direitos autorais daqueles que utilizam as obras musicais publicamente, os chamados "usuários de música", que somam 399 mil no cadastro do mencionado Escritório.

Existem quatro tipos de usuários de músicas, quais sejam: o permanente, que utiliza as obras musicais de maneira constante, habitual e prolongada em sua atividade profissional. Considera-se habitual a execução musical sempre que "o usuário, num mesmo local de que seja proprietário, arrendatário ou empresário, tiver efetuado no mínimo 8 (oito) espetáculos ou audições musicais por mês durante $10(\mathrm{dez})$ meses em cada ano civil”’3 bem como os empresários locais ou regionais que promovem espetáculos musicais em várias cidades, nas mesmas condições acima referidas; o eventual, sendo aquele que utiliza sem habitualidade tais trabalhos artísticos; o de Rádio/TV, o qual utiliza de obras musicais através de radiodifusão (emissoras de rádio e TV); e, por fim, as mídias musicais, representando aquele usuário que utiliza obras musicais através da internet, telefonia móvel e mídias digitais.

Os valores pagos pelos usuários de músicas são calculados com base nos critérios do Regulamento de Arrecadação desenvolvido pelos próprios titulares das músicas, através de suas associações musicais. Para tanto, é classificado, primeiramente, o nível de importância da música para a atividade ou estabelecimento, como indispensável, necessária ou secundária, e ainda é considerada a periodicidade da utilização (permanente ou eventual), inclusive, se a apresentação é feita por música mecânica ou ao vivo, com ou sem dança.

Assim, o valor a ser pago é calculado de acordo com as informações fornecidas pelo usuário e a forma de cobrança é determinada em função do parâmetro físico ou de percentual incidente sobre a receita bruta de quem está utilizando a música.

O ECAD, portanto, promove a defesa, arrecadação e distribuição dos direitos autorais de todos os titulares nacionais filiados às associações que o integram, assim como dos representantes estrangeiros, podendo, para tanto, praticar os atos necessários à defesa extrajudicial e judicial desses direitos, agindo em nome próprio como substituto processual, nos termos da Lei $\mathrm{n}^{\circ} 5.988 / 73$ e como também preceitua o parágrafo 2 do art. 99 da Lei $n^{\circ} 9.610$, razão pela qual o presente artigo se presta a discorrer sobre a atuação do ECAD na cobrança pela utilização do direito autoral.

\section{Análise Jurisprudencial da cobrança do Direito Autoral}

O ECAD, conforme foi visto, é organizado pelas associações de titulares de Direitos Autorais, nos termos do art. 99 da Lei $n^{0}$ 9.610/98, para exercer a prerrogativa exclusiva de arrecadar e distribuir, em todo o território nacional, a receita auferida a título de direitos autorais, em decorrência da utilização pública, por parte dos diversos tipos de usuários de obras musicais, lítero-musicais e de fonogramas.

$\mathrm{O}$ instituto repassa às associações de titulares o que é arrecadado daqueles que utilizam obras musicais em suas atividades. Assim, se alguém não paga os direitos autorais, os titulares das obras que foram utilizadas nada recebem.

Entretanto, o usuário inadimplente infringe a lei, ficando sujeito à lavratura de um “Termo de Verificação", que poderá acarretar a interdição ou a suspensão da execução pública musical, bem como procedimentos judiciais nos âmbitos cíveis e criminais. Sobre o tema, o Art. 105 da Lei dos Direitos Autorais dispõe o seguinte:

3 http://www.ecad.org.br/ViewController/publico/conteudo.aspx? codigo=437 acessado dia 20 de novembro de 2010, às $15 \mathrm{~h} 30$ 
Art. 105. A transmissão e a retransmissão, por qualquer meio ou processo, e a comunicação ao público de obras artísticas, literárias e científicas, de interpretações e de fonogramas, realizadas mediante violação aos direitos de seus titulares, deverão ser imediatamente $\underline{\text { suspensas ou interrompidas pela autoridade judicial competente, sem prejuízo da multa }}$ diária pelo descumprimento e das demais indenizações cabíveis, independentemente das sanções penais aplicáveis; caso se comprove que o infrator é reincidente na violação aos direitos dos titulares de direitos de autor e conexos, o valor da multa poderá ser aumentado até o dobro.(grifado)

Dessa forma, o ECAD, no exercício das prerrogativas que lhe foram deferidas por lei, quando constata que uma pessoa jurídica, no desempenho de sua atividade e interesses vem se utilizando, habitualmente, em diversos espaços e logradouros públicos, de obras musicais, lítero-musicais e fonogramas, promovendo apresentações (shows), deixando de pagar os valores devidos, a título de direitos autorais de execuções públicas de obras musicais, lítero-musicais e fonogramas, sem obter previamente a necessária autorização dos titulares dos direitos, tem competência para acionar o infrator da Lei, até mesmo judicialmente.

Visando regularizar essa situação e trazer o usuário de música à normalidade, o ECAD promove diversas tentativas suasórias, para ver satisfeito o pagamento dos direitos autorais, no intuito de não ser visto o descaso com a propriedade e direitos dos compositores musicais, cujas obras podem ser, indevidamente, apropriadas por terceiros, a cada evento que promove e/ ou participa, auferindo suas finalidades e proveitos.

Caso o usuário de música se furte ao pagamento de retribuição autoral, contraria, de forma inequívoca, o disposto no artigo 68, parágrafos $2^{\circ}$ e $3^{\circ}$, da Lei ${ }^{\circ} .9 .619 / 98$, in verbis:

Art. 68. Sem prévia e expressa autorização do autor ou titular, não poderão ser utilizadas obras teatrais, composições musicais ou lítero-musicais e fonogramas, em representações e execuções públicas.

$[\ldots]$

Parágrafo $2^{\circ}$. Considera-se execução pública a utilização de composições musicais ou lítero-musicais, mediante a participação de artistas, remunerados ou não, ou a utilização de fonogramas e obras audiovisuais, em local de frequência coletiva, por quaisquer processos, inclusive a radiodifusão ou transmissão por qualquer modalidade, e a exibição cinematográfica.

Parágrafo $3^{\circ}$. Considera-se locais de frequência coletiva os teatros, cinemas, salões de baile ou concertos, boates, bares, clubes ou associações de qualquer natureza, lojas, estabelecimentos comerciais e industriais, estádios, circos, feiras, restaurantes, hotéis, motéis, clínicas, hospitais, órgãos públicos da administração direta ou indireta, fundacionais e estatais, meios de transporte de passageiros terrestre, marítimo, fluvial ou aéreo, ou onde quer que se representem, executem ou transmitam obras literárias, artísticas ou científicas.

Portanto, caso o usuário não pague o direito autoral, mesmo com as tentativas extrajudiciais, outra alternativa não resta ao ECAD, senão ingressar com ação judicial, para verem sanados os insuportáveis prejuízos aos titulares das criações musicais utilizadas nos espetáculos.

Sobre o tema, inclusive, o Superior Tribunal de Justiça (STJ), em perfeita harmonia com a legislação autoral e com a Constituição Federal, já firmou jurisprudência sobre as questões envolvendo a cobrança da retribuição autoral, decorrente da promoção de eventos musicais, como se transcreve abaixo:

PROCESSO CIVIL. DECISÃO MONOCRÁTICA. EMBARGOS DECLARATÓRIOS. PRINCÍPIO DA FUNGIBILIDADE. AGRAVO REGIMENTAL. INDENIZAÇÃO POR DANOS MORAIS. DIREITO AUTORAL. ECAD. HOTEL. REPRODUÇÃO DE MÚSICA EM QUARTOS DE HOTEL. 
1. (..)

2. (...)

3. A disponibilização de sinal de rádio e televisão dentro dos quartos de um hotel não isenta o estabelecimento do pagamento de direitos autorais, exceto se são utilizados serviços de TV e rádio por assinatura de empresa fornecedora que, ao emitir o sinal dos programas, já tenha efetuado os respectivos pagamentos.

Isso porque tais programas são editados pela prestadora de serviços para uso exclusivo de determinados clientes, que os reproduzem em seus ambientes profissionais. Somente nesse momento é que é devido o pagamento de direitos autorais. Assim, se o fato gerador é único, feito um pagamento, tem-se por quitada a utilização da obra por autoria.

4. Embargos de declaração recebidos como agravo regimental, ao qual se dá parcial provimento.

(EDcl no REsp 1044345/RJ, Rel. Ministro JOÃO OTÁVIO DE NORONHA, QUARTA TURMA, julgado em 04/02/2010, DJe 11/02/2010)

CIVIL. RECURSO ESPECIAL. DIREITOAUTORAL. OBRAMUSICAL. CARNAVAL DE RUA. VIOLAÇÃO DE DISPOSITIVO CONSTITUCIONAL. DIVERGÊNCIA JURISPRUDENCIAL. CONFIGURADA.

1. Não se conhece de alegada violação de dispositivo constitucional sob pena de usurpação da competência do Supremo Tribunal Federal.

2. "A utilização de obras musicais em espetáculos carnavalescos gratuitos promovidos pela municipalidade enseja a cobrança de direitos autorais à luz da nova Lei $n^{\circ}$ 9.610/98, que não mais está condicionada à aferição de lucro direto ou indireto pelo ente promotor. II. Recurso especial conhecido e provido". (Resp 524.873/ES, Rel. Ministro ALDIR PASSARINHO JUNIOR, SEGUNDA SEÇÃO, julgado em 22/10/2003, DJ 17/11/2003 p. 199).

3. Denota-se da condenação a imposição de multa de vinte vezes - art. 109 da Lei ${ }^{\circ}$ 9.610/98 - somente deferida quando há manifesta comprovação de pirataria.

4. Recurso Especial conhecido em parte e, nesta extensão, provido parcialmente.

(REsp 700.240/RS, Rel. Ministro HONILDO AMARAL DE MELLO CASTRO (DESEMBARGADOR CONVOCADO DO TJ/AP), QUARTA TURMA, julgado em 19/11/2009, DJe 14/12/2009)

Pelas jurisprudências citadas, percebe-se que quando os entes políticos, no caso as Prefeituras Municipais, organizam espetáculos públicos, como shows e apresentações, eles devem pagar os direitos autorais dos artistas cujas músicas serão citadas.

Entretanto, diferentemente do que dispôs a jurisprudência do Superior Tribunal de Justiça, o Tribunal de Justiça do Estado do Ceará (TJ/CE) decidiu de forma a não ser cabível a cobrança de direitos autorais em eventos gratuitos, da seguinte forma:

REMESSA NECESSÁRIA E APELAÇÃO CÍVEL No 2002.0008.3776-5/0 COMARCA: SOBRAL

REMETENTE: JUIZ DE DIREITO DA 4 ${ }^{\mathrm{a}}$ VARA DA COMARCA DE SOBRAL

APELANTE: ESCRITÓRIO CENTRAL DE ARRECADAÇÃO E

DISTRIBUIÇÃO - ECAD

APELADA: PREFEITURA DE SOBRAL

RELATOR: DES. ANTÔNIO ABELARDO BENEVIDES MORAES

EMENTA: AÇÃO DE COBRANÇA. DIREITO AUTORAL. ECAD. MUNICÍPIO. EVENTO CARNAVALESCO GRATUITO REALIZADO EM LOGRADOUROS E PRAÇAS PÚBLICAS ANTES DA VIGÊNCIA DA LEI N 9.610/98. COBRANÇA INDEVIDA. LEI Nº 5.988/73. SENTENÇA MANTIDA. 
1. A sentença que não reconhece o direito pleiteado pelo Escritório Central de Arrecadação e Distribuição - ECAD, o qual possui natureza jurídica de entidade privada sem fins lucrativos, bem como a que indefere o pedido de reconvenção, não está sujeita ao reexame ex offício da matéria no Órgão ad quem.

2. O Município de Sobral, ao promover o carnaval de rua no ano de 1997, sob a vigência da Lei ${ }^{\circ} 5.988 / 73$, sem a cobrança de ingressos e sem o intuito de lucro, não estava obrigado a pagar direitos autorais relativos à utilização de obras musicais no evento popular.

3. In casu, é descabida a alegação de vantagem econômica indireta que beneficiou a municipalidade, uma vez que o evento carnavalesco possui a feição cultural e social de festa popular, com o objetivo de entretenimento dos foliões que frequentam o Município.

4. Reexame não conhecido. Apelo conhecido e desprovido. Sentença confirmada. (Julgamento em 19/10/2009)

Nota-se, porém, que é majoritária a posição do Superior Tribunal de Justiça em serem devidos os direitos autorais quando há utilização das canções pelos que se encaixam no conceito de usuário de músicas.

A despeito do acórdão do TJ/CE em sentido aposto, nos tribunais de $2^{\mathrm{a}}$ (segunda) instância, predomina também o entendimento do STJ. A título de exemplo, cite-se a ementa do Acórdão proferido pela SEGUNDA CÂMARA CÍVEL DO TJ DA BAHIA (TJ/BA), em $\underline{09.03 .2010}$, que preceitua da seguinte forma:

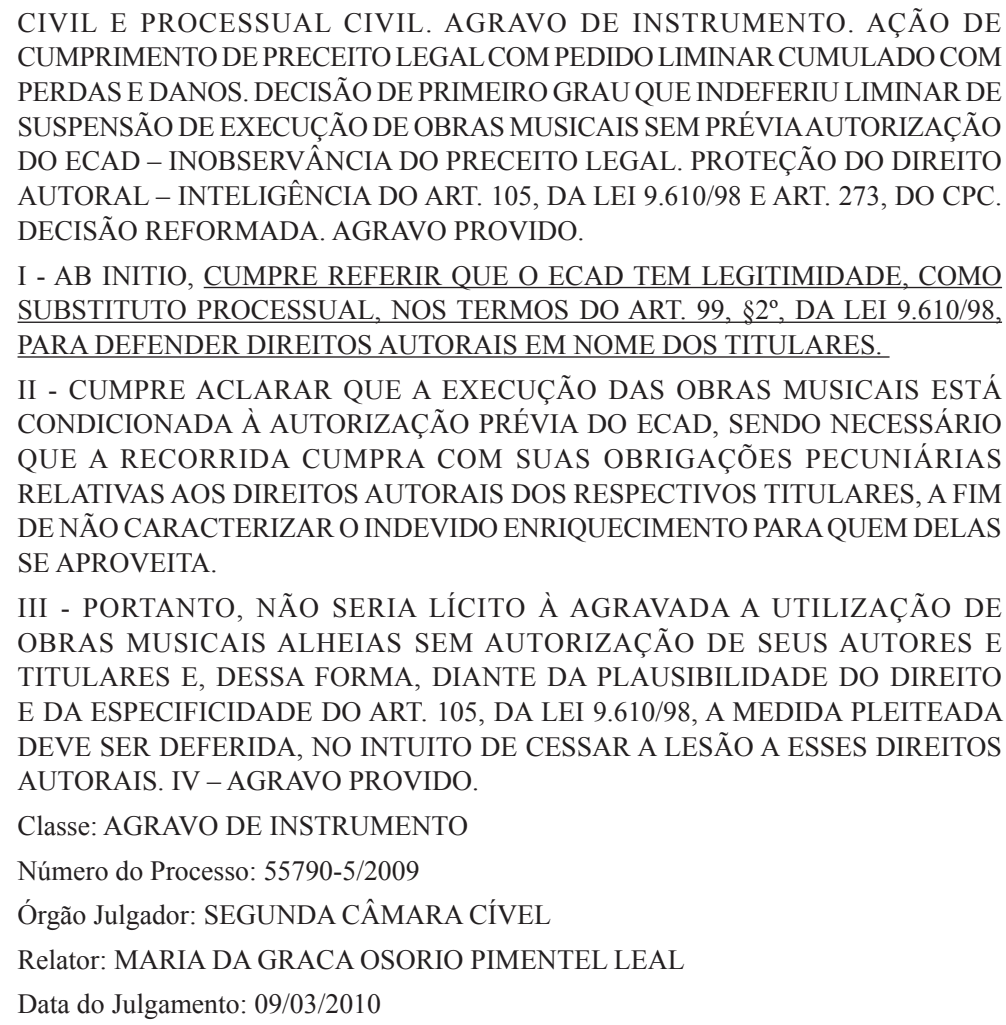

E ainda mais recente, com o mesmo entendimento supra aduzido foi o proferido, novamente, pelo $\mathrm{TJ} / \mathrm{Ba}$, , em processo do ECAD, julgado em 2008, nos seguintes dizeres: 
DIREITO AUTORAL. VIOLAÇÃO. ART. 105, DA LEI Nº 9610/98. PROVIMENTO DO AGRAVO.

I- A TRANSMISSÃO, OU EXECUÇÃO DE OBRAS MUSICAIS, HÁ DE RESPEITAR OS DIREITOS AUTORAIS, SOB PENA DE SER SUSPENSA.

II - EMPRESA AGRAVADA, EM DÉBITO COM O ECAD, NO QUE PERTINE AO RECOLHIMENTO DOS DIREITOS AUTORAIS.

III - PROVIMENTO DO RECURSO, PARA DETERMINAR-SE A SUSPENSÃO, SOB PENA DE MULTA DIÁRIA DE QUINHENTOS REAIS (R\$ 500,00) DA EXECUÇÃO E RADIODIFUSÃO DE OBRAS MUSICAIS, LITERO-MUSICAIS E FONOGRAMAS, ENQUANTO NÃO PROVIDENCIADA A NECESSÁRIA LIBERAÇÃO, JUNTO AO ECAD.

Classe: AGRAVO DE INSTRUMENTO

Número do Processo: 26152-9/2008

Órgão Julgador: SEGUNDA CÂMARA CÍVEL

Relator: LOURIVAL ALMEIDA TRINDADE

Data do Julgamento: $25 / 11 / 2008$

Cabe ressaltar, inclusive, que o ECAD não está obrigado, pelos autores e titulares das obras musicais, lítero-musicais e fonogramas (consoante parte "I", item 13, dos princípios gerais de cobrança, impostos no seu regulamento de arrecadação) a liberar eventos de usuários em débito, muito ao revés, onera-se em administrar e proteger o repertório das utilizações ilícitas.

Conforme já preceituado, o autor é titular de direitos morais e patrimoniais sobre sua obra, tendo o direito de autorizar, como também o de proibir o uso desautorizado de suas criações, pois a obrigação de abstenção se impõe erga omnes.

No mesmo sentido, o Egrégio Tribunal de Superior Tribunal de Justiça vem, recentemente, pronunciando, senão verifique-se o Acórdão a seguir:

AGRAVOREGIMENTALNORECURSOESPECIAL.ESPETÁCULOSCARNAVALESCOS PROMOVIDOS PELO MUNICÍPIO. DIREITO AUTORAL. POSSIBILIDADE DE COBRANÇA, INDEPENDENTEMENTE DA GRATUIDADE DO EVENTO. FATO POSTERIOR À EDIÇÃO DA LEI N. ${ }^{\circ}$ 9.610/98. AUSÊNCIA DE SIMILITUDE FÁTICA ENTRE O ACÓRDÃO RECORRIDO E AQUELES APONTADOS COMO PARADIGMA.

1. Possibilidade de cobrança de direito autoral em razão de espetáculos carnavalescos públicos realizados, ainda que gratuitamente, realizados sob a égide da Lei n. ${ }^{\circ}$ 9.610/98.

2. Distinção dos eventos gratuitos realizados anteriormente na vigência da Lei n ${ }^{\circ}$ 5988/73.

3. Inaplicabilidade dos julgados apontados como paradigma, por não guardarem similitude fática com a hipótese em comento.

AGRAVO REGIMENTAL DESPROVIDO.

(AgRg no REsp 730.007/RS, Rel. Ministro PAULO DE TARSO SANSEVERINO, TERCEIRA TURMA, julgado em 04/11/2010, DJe 22/11/2010)

CIVIL. DIREITOS AUTORAIS. SHOW AO VIVO PROMOVIDO PELO SESC. COBRANÇA DEVIDA. PRECEDENTES.

I. É devida a cobrança de direitos autorais de evento musical promovido pelo Serviço Social do Comércio - SESC, independente da cobrança ou não de ingressos.

II. Precedentes do STJ.

III. Recurso especial do autor conhecido e provido.

(REsp 908.476/SP, Rel. Ministro ALDIR PASSARINHO JUNIOR, QUARTA TURMA, julgado em 28/09/2010, DJe 15/10/2010) 
Assim, demonstrado que a jurisprudência, valendo-se dos textos legais, visa coibir abusos como os praticados pelo acionado, impõe-se o exame da matéria pelo órgão jurisdicional, de forma a prevalecer a ordem jurídica vigente e, definitivamente, através do mesmo Poder Judicante, proibir o uso ilegal e indevido das obras de criação do espírito, como a imposição da devida retribuição pecuniária em favor dos titulares das obras artístico-musicais e fonogramas.

Não se pode esquecer, entretanto, o fato de os servidores do ECAD não serem funcionários públicos, razão pela qual não gozam da presunção de veracidade dos atos administrativos. Assim, é necessário que o Escritório prove os atos constitutivos, extintivos ou modificativos de seus direitos, conforme julgado a seguir:

EMENTA: ECAD - AÇÃO DE INEXISTÊNCIA DE DÉBITO - ARRECADAÇÃO DE DIREITOS AUTORAIS - ECAD - ÔNUS DA PROVA DA EXECUÇÃO DE OBRAS MUSICAIS - Os agentes do ECAD não são servidores públicos e seus atos não gozam de presunção de veracidade, já que por sua qualidade não possuem fé pública. - Compete ao réu, ao contrapor os fatos alegados pelo autor, a prova dos fatos impeditivos, modificativos ou extintivos do direito sustentado na inicial, conforme o art. 333, II, do CPC.

APELAČ̃̃ CÍVEL N 1.0342.03.037401-7/001 - COMARCA DE ITUIUTABA - APELANTE(S): ECAD ESCRITÓRIO CENTRAL ARRECADAÇÃO DISTR APELADO(A)(S): FUND EDUCACIONAL ITUIUTABA - RELATOR: EXMO. SR. DES. NILO LACERDA

Ademais, é preciso lembrar que o ECAD não pode cobrar o valor dos direitos autorais de forma arbitrária, devendo observar a ordem preferencial de cálculos disposta no Regulamento de Arrecadação Consolidado daquela sociedade civil, regulamentada pela Lei $n^{\circ}$ 9.610/98. Além disso, suas cobranças não são tributos, razão pela qual, como foi expresso anteriormente, cabe a ele provar o fato constitutivo (modificativo ou extintivo) de seu direito, conforme julgado a seguir:

DIREITOS AUTORAIS SOBRE OBRAS MUSICAIS - COBRANÇA - ESCRITÓRIO CENTRAL DE ARRECADAÇÃO E DISTRIBUIÇÃO - ECAD - CRITÉRIO FÍSICO DE MENSURAÇÃO DA UTILIZAÇÃO DA OBRA (ÁREA DO SHOW) INADMISSIBILIDADE. A forma adotada pelo Brasil para a fixação de preços de direitos autorais é absolutamente arbitrária e monopolista, pretendendo o ECAD gozar de uma soberania que nem o Estado possui, pautada que está a Administração pelo Princípio da Legalidade. Se há proteção aos direitos autorais, também os do consumidor são tutelados, devendo haver razoabilidade e proporcionalidade entre as várias esferas da tutela prestada pelo Direito. A fixação dos preços de direitos autorais com aplicação de parâmetro físico e potência da transmissora, constitui critério absolutamente inadequado, já que leva em consideração a área sonorizada. O ECAD, na verdade, apresenta-se em Juízo munido de uma espécie de clone de "'"certidão de dívida ativa"', que seria absolutamente indiscutível pelos consumidores, e a cuja tarefa se reservaria a prova em contrário, à feição dos privilégios que a lei prevê para os créditos tributários. Procura criar, na realidade, uma tipo novo de título de crédito, que se poderia chamar de ""certidão de dívida ativa de direitos autorais"”, não autorizada legalmente. (TJ/MG Processo $n^{\circ} 1.0000 .00 .347379-0 / 000$ )

Relator: KILDARE CARVALHO

Data do Julgamento: 30/04/2009

Data da Publicação: 26/06/2009

EMENTA: AÇÃO DE COBRANÇA - DIREITOS AUTORAIS - ECAD - LEI No 9.610/98 - FORMA DE CÁLCULOS -REGULAMENTO DE ARRECADAÇÃO CONSOLIDADO - CRITÉRIO - ORDEM PREFERENCIAL - OBSERVÂNCIA - SENTENÇA MANTIDA. A fixação dos valores devidos ao ECAD, a título de arrecadação de direitos autorais, deve observar a ordem preferencial de cálculos disposta no Regulamento de Arrecadação Consolidado daquela sociedade civil, regulamentada pela Lei ${ }^{\circ}$ 9.610/98. Sentença mantida em reexame necessário, prejudicado o apelo voluntário. 
APELAÇÃO CÍVEL / REEXAME NECESSÁRIO N 1.0508.06.002383-7/001 COMARCA DE PIRANGA - REMETENTE: JD COMARCA PIRANGA-APELANTE(S): ECAD ESCRITÓRIO CENTRAL ARRECADAÇÃO DISTR - APELADO(A)(S): MUNICÍPIO PRESIDENTE BERNARDES - RELATOR: EXMO. SR. DES. KILDARE CARVALHO (TJ/MG Processo no 1.0508.06.002383-7/001)

Portanto, o ECAD goza de legitimação ativa para cobrança dos direitos autorais, mas não goza da presunção de veracidade de suas alegações, devendo, também, para as suas cobranças, observar valores previamente estabelecidos e regulamentados pela Lei $\mathrm{n}^{\circ}$ 9.610/98.

\section{Conclusão}

Pelos aspectos apresentados no presente trabalho, percebeu-se que os criadores de músicas, ainda que sem letra, possuem ampla proteção constitucional e legal de suas obras, podendo exigir, inclusive, contraprestação pecuniária por qualquer espécie de uso ou publicação de sua criação.

A Constituição Federal de 1988, por exemplo, confere exclusividade ao autor sobre suas obras, no art. $5^{\circ}$, inciso XXVII, dizendo que cabe aos autores o direito exclusivo de utilização, publicação ou reprodução de suas obras, transmissível aos herdeiros pelo tempo que a lei fixar. Aliás, está sob a rubrica Dos Direitos e Deveres Individuais e Coletivos, o que, por si só, já caracteriza o núcleo irredutível da Constituição.

Sobre direito autoral, inclusive, o próprio Supremo Tribunal Federal editou uma súmula, garantindo, pela execução de obra musical por artistas remunerados, ser devido direito autoral, não exigível quando a orquestra for de amadores."

Foi visto, também, que a Lei no. 9.610/98, denominada Lei de Direitos Autorais, entre outros aspectos, impõe a obrigação legal direcionada a todos as pessoas de não utilizar as obras musicais em suas programações sem a devida autorização dos titulares de direitos autorais.

Assim, demonstrando a importância na proteção de obras intelectuais, o Constituinte Originário elevou a nível Constitucional a exclusividade do autor de obras intelectuais exercer seus direitos, no sentido de ser ele a única pessoa que pode exercer as prerrogativas advindas das obras protegidas.

Com objetivo, então, de cuidar da arrecadação e distribuição, em comum, dos direitos relativos à execução pública das obras musicais e lítero-musicais e de fonogramas, inclusive por meio da radiodifusão e transmissão por qualquer modalidade, e da exibição de obras audiovisuais, foi criado o ECAD. Este instituto é uma sociedade civil, pessoa jurídica de direito privado, instituído pela Lei Federal n ${ }^{\circ}$ 5.988/73 e mantida pela atual Lei de Direitos Autorais brasileira $-\mathrm{n}^{\circ}$ 9.610/98.

$\mathrm{O}$ ECAD atua judicial e extrajudicialmente na proteção dos direitos autorais. Como o presente trabalho se presta a fazer uma análise jurisprudencial, no âmbito do Poder Judiciário, portanto, dessa atuação, no terceiro tópico, foi discorrido vastamente sobre as decisões de juízes no que diz respeito aos direitos autorais pleiteados pelo ECAD.

Dessa forma, observou-se que tanto a jurisprudência do Superior Tribunal de Justiça (STJ), como dos Tribunais de Justiça - órgãos de $2^{\mathrm{a}}$ (segunda) instância do Poder Judiciário Estadual -, são majoritárias em deferir, tanto em sede liminar, como em via exaustiva, a proteção dos direitos autorais, determinando, inclusive, o espetáculo público que esteja acontecendo sem a devida regularização no que diz respeito a esses direitos. 


\title{
REFERÊNCIAS
}

ABRÃO, Eliane Y. Direitos de autor e direitos conexos. São Paulo: Editora do Brasil, 2002

BRASIL. Constituição da República Federativa do Brasil. 34. ed. São Paulo: Saraiva, 2005. . Lei 9.610/98, de 19 de fevereiro de 1998 - Lei de Direitos Autorais. . Lei ${ }^{\circ}$. 5.988, de 14 de Dezembro de 1973 - Antiga Lei de Direitos Autorais. . Ministério da Cultura. Direito Autoral - Brasília: Ministério da Cultura, 2006 (Coleção Cadernos de Políticas Culturais; v.1)

BITTAR, Carlos Alberto A. O direito de autor nos meios modernos de comunicação. São Paulo: Revista dos Tribunais, 1989.

BOBBIO, Vicente. O Direito de Autor na creação musical. São Paulo: Lex, 1951.

CABRAL, Plínio. Direito Autoral: dúvidas \& controvérsias. São Paulo: Habra, 2000.

CHAVES, Antonio. Obras literárias e musicais: Contrato de edição. São Paulo: Julex, 1988. CONSELHO NACIONALDE DIREITOAUTORAL. Legislação e normas. 3. ed. Brasília: CNDA, 1985.

FILHO, Francisco Humberto Cunha. Cultura e Democracia na Constituição Federal de 1988 - A representação de interesses e sua aplicação ao Programa Nacional de Apoio à Cultura. RJ: Letra Lega, 2004.

FRAGOSO, João Henrique da Rocha - Direito Autoral: Da Antiguidade à Internet. São Paulo: Editora Quartier Latin do Brasil. 2009.

NAZO, Georgette N. A Tutela jurídica do direito de autor. São Paulo: Saraiva, 1991.

OLIVER, Paulo. Direito autoral e sua tutela penal.: lei ${ }^{\circ}$ 9.609/98, lei $n^{\circ}$ 9.610/98, decreto-lei no 2.556/98. São Paulo: Ícone, 1998. p. 269.

SILVEIRA, Newton. A Propriedade intelectual e as novas leis autorais. 2.ed. São Paulo: Saraiva, 1998.

\section{AUTHOR LAW - THE ROLE OF ECAD ACCORDING TO BRAZILIAN COURTS}

\begin{abstract}
The Brazilian Constitution ruled as fundamental right the protection of intellectual/artistic work. This article analyzes the current federal law n. 9.610/98, called Author Law, and the rulings of Brazil's superior courts regarding the role of ECAD, the central office in charge of supervising the public execution of musical pieces.
\end{abstract}

Keywords: Author Law. ECAD. Law n. 9.610/98 